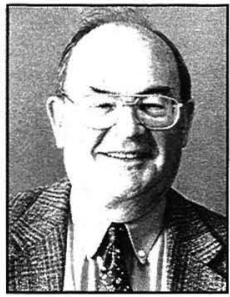

\title{
COMPANY EMPLOYMENT POLICIES \\ AND PRACTICES IN THE USE OF IMMIGRANT LINGUISTIC AND CULTURAL SKILLS
}

\author{
Noel Watts and Andrew Trlin
}

Massey University

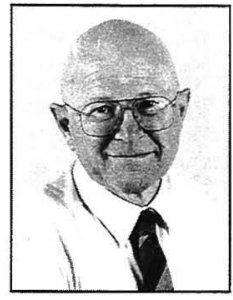

In recent years New Zealand's immigration policy has placed an emphasis on increasing human capital through encouraging well qualified immigrants to settle in New Zealand. Apart from the qualifications and work skills that immigrants bring from their countries of origin, they also possess, in many cases, proficiency in other languages as well as an understanding of other cultures. To what extent are these linguistic and cultural resources utilised in New Zealand employment? This paper examines the policies and practices of companies engaged in the international business sector to determine the factors that influence effective use of this pool of expertise. The paper draws upon the findings of a survey of companies involved primarily in exporting and tourism, as well as follow-up interviews with selected companies. On the basis of this study, best practice features in the use of immigrant linguistic and cultural resources are identified.

Keywords: immigrants, employment policies, language, culture exporting, tourism

This paper discusses issues relating to the policies and practices of New Zealand companies in relation to the employment of immigrants from non-English speaking backgrounds (NESB). In particular, it focuses on issues relating to the use of their native-speaker proficiency and cultural understanding in international business dealings. The significance of this topic stems from moves in recent years to widen the scope of immigration from non-traditional sources in order to add to the nation's human capital, encourage enterprise and innovation, secure funds for investment and to strengthen international business, trade and tourism linkages (see New Zealand Immigration Service, 1995a and 1995b; Trlin, 1997). The question then needs to be asked whether the language skills and cultural competencies of NESB immigrant employees are being used effectively by New Zealand companies, especially those engaged in international business.

The paper draws on the findings of a survey of the utilisation of immigrant language resources conducted in $\mathrm{Au}-$ gust-October 1998. The survey forms part of the New Settlers Programme (NSP), a multidisciplinary research project designed and conducted by Massey University staff and supported by the Foundation for Research, Science and Technology. The general aim of the NSP is to contribute to the attainment of three broad, interrelated outcomes:

- the development of a balanced, well integrated institutional structure of immigration (see Trlin, 1993 for a definition and discussion);

- a reduction in the difficulties experienced by immigrants in the process of resettlement;

- an increase in the benefits accruing to New Zealand from its targeted immigration programme.
For further details on the NSP, see Trlin et al. (1998),

The survey has been carried out to help fill the large gaps in research with regard to the employment of NESB immigrants, and the use of their native language skills and cultural competencies in particular. Research carried out into the role of languages other than English in business has tended not to differentiate between the use of the foreign language knowledge of New Zealand-born employees and the native-speaker skills of NESB immigrants (Dunmore and Rollason, 1966; Dunmore and Brooker, 1976; Levett and Adams, 1987; Watts, 1987, 1992; Enderwick and Gray, 1992; Watts and Williamson, 1994).

The study has three components: (a) a postal survey of companies involved in international business; (b) follow-up interviews with selected companies; and (c) a postal survey of a group of immigrants who have obtained higher level tertiary qualifications in New Zealand. The postal survey was conducted in August-September 1998. A total of 460 companies and organisations received questionnaires; 215 questionnaires were returned of which 28 were uncompleted. This represents a return rate (for the $187 \mathrm{com}$ pleted questionnaires) of $41 \%$. In the second stage of the project, follow-up interviews were conducted in September-October 1998 with 19 companies in the main centres (Auckland, Wellington, Christchurch and Dunedin), as well as in provincial towns and cities (Marton, Napier, Palmerston North). The third stage, involving a survey of immigrants who have completed higher level tertiary stud.ies in the business field was still in progress at the time of writing this paper.

In the following sections of this paper, a brief overview is given of the kinds of immigrant employment policies and 
practices reported by the companies that participated in the study. This is followed by a more detailed discussion of the factors that may have influenced company policy formulation and implementation. The paper concludes with the identification of best practice features and suggestions for further research.

\section{General policies on immigrant recruitment}

Of the 187 companies that completed questionnaires, only 21 reported an explicit company policy concerning immigrants. These responses are presented according to company categories in Table 1. For the purposes of this study, the categories may be defined as follows: "tourism" includes in-bound tour operators, as well as companies involved in tourism information and services; "exporting" refers to companies involved in the production and/or marketing of foods and beverages and other manufactured goods; and the "other" category refers mainly to companies involved in a variety of activities that range from the provision of technical or financial services to consulting.

Table 1. Number of companies with policies on immigrant recruitment by company categories

\begin{tabular}{lr|r|r}
\hline & Tourism & Exporting & Other \\
\hline $\begin{array}{l}\text { Number of companies } \\
\text { in the survey }\end{array}$ & 88 & 88 & 11 \\
$\begin{array}{l}\text { Companies with explicit } \\
\text { policies on immigrant } \\
\text { recruitment }\end{array}$ & 13 & 7 & 1 \\
\hline
\end{tabular}

Source: 1998 Survey of the utilisation of immigrant resources, Watts and Trlin

Respondents from the 21 companies with explicit policies on immigrant recruitment reported the following as examples of policy guidelines in place.

\section{Need to recruit the best applicants}

Many of the comments on staff recruitment emphasised the need to recruit the best applicants available for specified positions, regardless of their country of origin. As one exporting company reported: "We are a global multinational company and expect movement between countries of staff for various projects. So we look globally for key positions when recruiting".

\section{Recruitment for particular positions that cannot be filled locally}

For some positions, recruitment would have to be made offshore, as applicants with the necessary competencies were difficult to obtain in New Zealand. Examples of professionally qualified personnel in short supply were computer programmers and software developers. Two occupational areas mentioned which required a particular blend of work experience and cultural background not easily found in New Zealand, were Halal butchers and Chinese chefs.
3. Recruitment for positions involving cross-cultural communication skills

Respondents reported that some positions required people familiar with cross-cultural communication environments. Recruitment for these positions could either be made locally amongst the pool of immigrants with work permits or New Zealand resident status, or through overseas employment agencies. The most frequently cited positions in this category were tour guides, tour co-ordinators and sales assistants in duty free shops. A more specific case was that of co-ordinators of joint ventures between New Zealand and overseas companies such as fishing arrangements with Russian-based interests.

\section{English requirements}

Competency in English was emphasised as a critical consideration. Typical of the responses received is this stipulation of a tourism company engaged in transportation services: "Immigrants must possess above average communication ability - both verbal and written". One exception noted was the case of Cantonese-speaking chefs where no contact with the English-speaking public was involved.

\section{Affirmative action}

One company (engaged in casino operations) endorsed affirmative action in respect to providing special employment opportunities for minorities. As the company commented: "We want our workforce to reflect the community."

\section{Immigration status}

A number of the companies identified immigration status as a major consideration in recruitment plans. For example: "Immigrants must possess a work visa" and "Must be a New Zealand resident." This was emphasised even more forcibly in the follow-up interviews. Interviewees complained of problems with immigration authorities and said that this had influenced their companies, persuading them to recruit only within New Zealand. As the human resources manager of an in-bound tourism company observed: "We've only recruited offshore once. That was in the early days and we would never do it again...The Immigration Department just made our life a nightmare."

\section{Specific language-related policies}

As far as specific polices relating to language were concerned, 34 of the 187 companies reported that they recruited NESB immigrants for certain positions primarily on the basis of their native-speaker skills. Twenty-three companies also indicated that it was company policy to maintain a list or register of the capabilities of staff in languages other than English (though some of the smaller companies said that there was no need for a formal record of languages spoken by staff as they were well aware of the skills of their employees). However, only 17 companies indicated that they had a policy of rewarding staff for their competency in languages other than English, either through bonuses or through enhanced advancement opportunities. Forty companies indicated they would provide assistance 
for NESB immigrants to improve their English language skills if required.

As can be seen in Table 2, tourism companies are the most likely to have language-specific policies. No doubt this reflects the primary importance of face-to-face, provider/ client communication in the tourism industry.

\section{Practices related to the use of NESB immigrants' linguistic and cultural skills}

Although only a small number of the 187 companies surveyed indicated that they had policies relating to immigrant recruitment, a considerably larger number reported that they utilised in different ways the linguistic and cultural skills of their NESB immigrant employees. A brief summary of company practices is given below.

\section{Use of NESB immigrants' linguistic skills}

Of the 187 companies that responded, 130 employed NESB immigrants. Of these companies, $97(74.6 \%)$ reported that use was made at work of the native languages of employees in some way. Greater use of NESB immigrant language skills was noted in companies in the "tourism" category; 57 (91.9\%) companies that employed NESB migrants indicated that use was made of NESB language skills, compared with $32(55.2 \%)$ of the companies in the "exporting" category and $8(80 \%)$ companies in the "other" category.

This utilisation of immigrant employee language skills can be broken down further into: work-related communication with other staff; use with customers or clients; and social use with other staff. The highest percentage of responses was for use of languages with customers or clients, particularly in the "tourism" and "other" categories (Table 3). Companies in the "exporting" category indicated greater use of languages in the area of "social use with other staff", possibly because of the larger proportion of immigrant $(\mathrm{Pa}$ cific Island) workers in semi-skilled production areas. Overall, the main tasks involving the use of immigrant employee

\section{Table 2. Language-related policies by company categories}

\begin{tabular}{lccr}
\hline & Tourism & Exporting & Other \\
\hline $\begin{array}{l}\text { Companies targeting } \\
\text { recruitment of native } \\
\text { speakers of languages } \\
\text { other than English }\end{array}$ & 27 & 4 & 3 \\
$\begin{array}{l}\text { Companies keeping a } \\
\text { register of proficiency }\end{array}$ & 16 & 6 & 1 \\
$\begin{array}{l}\text { in other languages } \\
\text { Companies with policies } \\
\text { on rewardsfor proficiency } \\
\text { in other languages }\end{array}$ & 12 & 5 & 0 \\
$\begin{array}{l}\text { Companies with policies } \\
\text { on assistingimmigrants } \\
\text { with English }\end{array}$ & 22 & 14 & 4 \\
\hline & & & \\
\end{tabular}

language skills were assisting overseas clients, translating, interpreting and correspondence.

\section{Use of the cultural backgrounds of NESB immigrants}

Reported use of the cultural backgrounds of NESB migrants was lower than the use of their language skills ("tourism" 37; "exporting" 15; "other" 3).

The cultural backgrounds of employees were drawn on mainly in staff development to assist other staff to gain an appreciation of the overseas customer base. Topics covered included greetings, customs and traditions, differences in living patterns and business etiquette. More specifically, companies involved in tourism hospitality referred to the importance of cultural input in the planning of menus and food preparation to suit the dietary preferences or requirements of overseas visitors. Meat exporting companies were obliged to follow Halal customs in preparing meat for export to Muslim countries.

Other ways in which the cultural backgrounds of NESB staff were employed included: meeting and welcoming overseas visitors on arrival; providing advice for staff travelling overseas; and advising on protocols when hosting senior management from overseas parent companies or offshore affiliates.

\section{Use of the business connections of NESB migrants}

Twenty companies in the "tourism" category, 17 in the "exporting" category and 1 in the "other" category reported that they utilised the business connections of immigrants. Business connections were seen as valuable by those who responded positively in this area of the questionnaire. Such connections gave market insights that would not normally be available to "outsiders". As examples, respondents referred to customer links that had been established in countries such as China, Japan and Malaysia by immigrant employees prior to their resettlement in New Zealand. A further area of advantage to New Zealand companies was the network of peers in scientific and technological fields. This network enabled immigrants working in research to keep themselves informed of new developments in their countries of origin, developments which could have a significant commercial potential for their companies.

\section{Key factors influencing company employment policies and practices}

What key factors may influence company employment policies and practices concerning the use of the linguistic and cultural skills of NESB immigrant employees? Three main factors emerged from the survey - the kind of activity involved, the customer base and attitudes to immigration each of which is briefly discussed below.

As we have noted with regard to the kind of activity involved, companies in the "tourism" category tend to see more advantage in using the linguistic and cultural skills of immigrants than those in the "exporting" or "other" categories. This is understandable as tourism is a people-orientated industry and entails a high degree of face-to-face 


\section{Table 3 The use made of NESB immigrant skills in languages other than English by}

company categories

\begin{tabular}{lccc}
\hline & Tourism & Exporting & Other \\
\hline $\begin{array}{l}\text { Companies in which other languages are used } \\
\text { for work-related communication among staff }\end{array}$ & 31 & 17 & 5 \\
$\begin{array}{l}\text { Companies in which other languages are used } \\
\text { with customers/clients }\end{array}$ & 56 & 20 & 5 \\
$\begin{array}{l}\text { Companies in which other languages are used } \\
\text { for social purposes among staff }\end{array}$ & 30 & 22 & 3 \\
\hline
\end{tabular}

communication with clients from different backgrounds. On the other hand, contacts with customers in the exporting sector are often less immediate, conducted at a distance and involve the written medium. As other studies have shown (Watts, 1987; 1992), outside agencies are often contracted to provide translation services.

The customer base is clearly a major determinant. The proportion of trade with countries where English is not the main language will obviously affect company decisions as to whether or not staff are required with specialist skills in other languages. As in-bound tourism companies tend to target regions, they have specific language priorities that relate to their clients' language needs. These needs may vary according to the age of clients and whether they prefer to travel in conducted groups, accompanied by guides or as independent travellers.

Apart from the practical considerations of the kind of activity involved and a company's customer base, attitudinal factors may also play a significant part in shaping company policies and practices. The general comments on policies and practices made by respondents revealed a wide range of both positive and negative attitudes towards immigrants. Positive attitudes are evident in responses indicating that immigrant employees were hard working, conscientious and reliable. Some respondents saw them as possessing a "work ethic" which exceeded that of Kiwi employees.

Consider, for example, the following quotes:

"They usually work harder as they have higher standards."

"Excellent workers - willing to please."

However, somewhat more negative observations were also made as illustrated in the following extracts:

"I don't think their qualifications are to the same standard as in NZ."

\section{"Communication can be very difficult."}

"Initially you are not certain of their transfer into the NZ way."

As far as negative attitudes are concerned, views on the English language ability of immigrants merit special mention. There was, at times, a discrepancy in the responses of companies; $99.2 \%$ reported that the English proficiency of their immigrant employees was adequate for work purposes, but some then proceeded to make negative comments on the English ability of immigrants in general:

\section{"If their English was better it would be an asset to them."}

"It should be compulsory that they should be able to pass 6th Form English and be tested annually for 5 years at their own expense."

This discrepancy seems to suggest that the stereotype of the immigrant as a poor speaker of English is widespread.

\section{Other factors influencing company employment policies and practices}

In addition to the three key factors identified and discussed above, there are a number of other influential factors

1. At a time of economic downturn, competition for available positions is keen and for a variety of reasons New Zealand employers may give preference to local, New Zealand-born applicants as Boyer (1996: 70) has noted in a study of the work experiences of Taiwanese immigrants in Auckland.

2. Enderwick and Gray (1992), on the basis of their research among New Zealand exporting companies, conclude that it is in the more senior positions that proficiency in other languages is seen to be the most useful. Similarly, Shaw (1996) found that language skills were mainly used in the middle and upper managerial levels in her sample of exporting firms and tourism companies in Canterbury. For this reason language skills may not be utilised to any marked degree until immigrants work themselves up to more senior positions.

3. Certain languages are in greater business demand than others. For example, in recent years Asian languages have been considered more relevant to trade than some European languages, and considerably fewer opportunities are available for Pacific Island immigrants to use their languages as part of their work.

4. Although a particular language may be useful to a company, there may not be the volume of work to justify full-time employment of a person with high levels of fluency in that language. A case in point is that of tourist guides who are normally employed as 'linguists' on 
a casual basis to accompany tour parties whenever the need arises.

5. Monolingual attitudes in the community (Waite, 1992) may influence company decisions concerning the recruitment and deployment of NESB immigrants. At the wider level, some companies appear to subscribe to the view that English is acceptable universally as a medium for business and use this as a justification for not seeking employees proficient in other languages. More specifically, companies may have concerns that the general public might have difficulty in coping with staff with accented English. In this respect, the Department of Internal Affairs (1996) reported claims by some immigrants that they had been discriminated against by New Zealand employers on the basis of accent even though they were fluent in English. Friesen and Ip's (1997) study of Chinese immigrants in Auckland also notes that a large proportion of their well-qualified sample were unemployed or under-employed despite the fact that many were proficient in English.

6. There is also the question of the degree of communicative competence that the immigrant has in his or her "native language". The term "native speaker" is problematic as "native speakers" can differ considerably in their linguistic repertoires. In the case of immigrants, the situation is complicated by factors such as pre-migration experience in business discourse. Before selecting staff to conduct sensitive business transactions in another language, New Zealand companies must be confident that they have mastery of the language of negotiation as well as a command of the lexicon related to the particular service or product area.

\section{Immigrant perceptions of company policies and practices}

Company attitudes towards immigrants can be compared with the perspectives of the immigrant workers themselves. The responses (in the completed questionnaires received to date) from NESB immigrants who hold tertiary level New Zealand qualifications in the business field, have highlighted the ways in which immigrants could contribute to New Zealand business performance and have also identified the problems faced by immigrants in realising their potential.

1. Value of NESB immigrants to the New Zealand economy:

"Migrants' experiences [in business] can assist $N Z$ in the export market".

"Advantage of immigrants' networks in home countries."

"Helps to expand the customer base where customers do not speak English or prefer to speak their native language (i.e. banking)."

"Bridges cultural gaps between customers and company."

"Innovations come often from the variety of experiences of people that come from different cultures."
In essence, views of the kinds cited above reinforce the practices of companies which make effective use of immigrants' linguistic and cultural skills, and confirm also the importance of factors such as the type of company activity and the nature of the customer base. If these views are widespread among professionally qualified NESB immigrants, it signals to employers the availability of a pool of people able and willing to put their native language and cultural skills to use in the marketplace. The fact that they have New Zealand tertiary qualifications is a bonus in that it means they have at least some understanding of the characteristics, peculiarities and requirements of local business activity.

2. Ways in which NESB immigrant employees could be used to better advantage:

"Involve immigrants in work groups, seminars to draw on their experiences."

"[Should be used more to] develop overseas market opportunities and also the local ethnic market."

Once again the previously identified practices of New Zealand companies are validated and the points made above in relation to the value of NESB immigrants apply here also. One additional point, however, concerns the local ethnic market which (though relatively small) is heavily concentrated in the Auckland and Wellington urban areas. Obviously, companies specialising in the provision of goods and services for the domestic market may have an opportunity here if they harness the assistance of NESB immigrant employees. It is, of course, an opportunity that might exist also in the ethnic enclaves of Australia and the west coast of North America.

\section{Problems encountered}

As expected, the respondents have also drawn attention to a range of problems that in one way or another impede the utilisation of their skills. Included among these problems are: the difficulty of actually finding a job; an apparent reluctance by many New Zealanders to adjust to the new immigration environment, to recognise the potential contribution of immigrants and to accommodate them within the structure and operation of companies accordingly; and finally, the perennial problems of racism and discrimination. In each case the difficulty noted or problem encountered echoes those mentioned by new settlers from China and India included in the NSP longitudinal study (in progress) and/or reported in other studies of skilled immigrants in New Zealand in the 1990s (see Boyer, 1996; Department of Internal Affairs, 1996; Lidgard, 1996).

\section{Best practice features}

It has been demonstrated in this paper that there is a wide range of perspectives on the use of the language and cultural skills of NESB immigrants in New Zealand companies engaged in international business. How, then, can we sum up best practice features in the use of these skills and competencies? On the basis of the responses of companies 
in the postal survey and the more detailed exploration of company strategies in the follow-up interviews, we can identify the following best practice features.

\section{General}

Best practice in recruitment involves the development of explicit recruitment and appointment policies that identify the advantages immigrants might bring to a company. These policies set out procedures for both attracting immigrant staff and settling them effectively into the workforce. Consideration is given to the fact that some immigrants might require additional training or retraining to make better use of their skills and qualities in the New Zealand work environment. Procedures are outlined in the recruitment and appointment policies for providing this additional support.

\section{Personal assistance (pre-arrival, on-arrival and later)}

Companies exemplifying best practice in the pre-arrival period make personal contact with potential immigrants in their countries of origin, provide them with accurate information about employment and living conditions in New Zealand, and assist them in completing immigration formalities. Effective on-arrival assistance involves greeting immigrants, placing them into suitable accommodation, helping them to choose schools for their children and facilitating their contact with community networks (including links with other members of their ethnic group). Depending on the circumstances of the immigrants, best practice follow-up assistance could include providing access to English language courses or to professional or vocational courses that could help the immigrants in their employment.

\section{Involvement in the company culture}

Best practice in integrating immigrants into the company involves induction programmes that focus on the needs of immigrants and provide them with knowledge and understanding of the company culture. Recent immigrants may also be called upon to contribute to staff development programmes that aim to increase the multicultural and multilingual awareness of company staff.

\section{Identification and recognition of immigrant linguistic skills}

The level of language skills of immigrants joining the workforce is assessed and noted in a company register. This listing is used as a reference point when the need arises. Recognition is given for competency in languages commercially useful to the company through a rewards system for foreign language proficiency.

\section{Effective use of linguistic and cultural skills}

Best practice in this area entails consideration of the language and cultural resources available among immigrant employees before contracting out language services to translation or interpreting agencies. Speakers of other languages are encouraged to maintain or extend their fluency and to gain qualifications as translators or interpreters. Consid- eration is given to training selected native speakers of other languages to take up specialist positions in the company where their language and cultural skills could be used to better advantage.

An exemplar of some of the best practice features referred to above is a well-established South Island malting company which exports $50 \%$ of its products overseas. The manager is himself an immigrant and has some skills in Japanese. Professional staff are recruited because of their expertise in barley breeding in other countries. The Spanish language skills of a staff member from Panama are employed in monitoring co-operative barley breeding projects in Uruguay while a Swedish-speaking staff member contributes to the development of joint venture projects in Northern Europe. Immigrant staff are also involved in carrying out information-gathering tasks in regions where they have a knowledge of the language. Speakers of other languages, such as German, also play a role in keeping up with scientific papers related to the industry which appear in foreign language journals and in monitoring scientific and commercial information on the internet.

\section{Conclusion}

A snapshot of the ways in which 187 companies report on their policies and practices concerning the language and cultural skills of their immigrant employees may not accurately represent how all New Zealand companies involved in international business make use of these resources. The picture may well be more positive than that portrayed above. On the other hand, it could equally well be argued that the 187 companies which responded out of the 460 which received postal questionnaires were those most interested in issues conceming the recruitment and deployment in the workforce of immigrants; hence the overall picture could be somewhat more negative. However, if these limitations are accepted then it can be suggested that there is evidence in the study that leads to the conclusion that New Zealand companies could make more effective use of the skills and understandings of employees who hail from countries where English is not spoken as a first language. As one respondent commented: "Unfortunately, NZ employers are not widely aware of the immigrants' skills and potential. That needs to be spoken of." This in turn may be related to a more fundamental problem alluded to by another respondent: "New Zealanders do not give a fair chance to new immigrants. They [immigrants] must go through a long and agonising process of acceptance by NZers. I speak with experience."

Needless to say, the sooner these and other issues identified and discussed in this paper are tackled, the sooner will New Zealand achieve (a) a reduction in the difficulties experienced by immigrants in the resettlement process; and (b) an increase in the benefits that ought to accrue from its targeted immigration programmes. More specifically, for companies involved in international business there is the potential to realise the benefits of the 'success equation' that has frequently eluded companies oriented to the domestic market (see Goulter, 1996). 


\section{Future Research}

Research needs in the area of languages and business, and in related areas that have been referred to in this paper, are summarised below:

1. Further research at the individual company level into the policies and practices that govern the employment of NESB immigrants.

2. Studies of language use in ethnic businesses in New Zealand.

3. Investigations into the design of specialist programmes which could help immigrants combine further development of their language skills with business management studies.

4. Examinations of the services offered by government departments as well as non-government agencies to assist immigrants with business advice, recognition of qualifications, translation of documentation etc.

5. An investigation into the feasibility of establishing an Industry Language Council to advise business and industry on language needs and to co-ordinate existing programmes and services geared to the satisfaction of such needs.

\section{References}

Boyer, T. (1996) Problems in paradise: Taiwanese immigrants in Auckland, New Zealand, Asia Pacific Viewpoint, 2 (1): 59-79

Department of Internal Affairs (1996) High hopes: a survey of qualifications, training and employment issues for recent immigrants in New Zealand Wellington: Department of Internal Affairs

Dunmore, J. and Brooker, G. (1976) Foreign languages and the New Zealand exporter: a reassessment Palmerston North: Department of Modern Languages, Massey University

Dunmore, J. and Rollason, B. (1966) Foreign languages and the New Zealand exporter Palmerston North: Department of Modern Languages, Massey University

Enderwick, P. and Gray, D. (1992) Foreign languages in international business: the case of New Zealand Journal of Teaching in International Business, 4: $49-68$

Friesen, W. and Ip, M. (1997) New Chinese New Zealanders: profiles of a transnational community in Auckland. In Bedford, R. and Spoonley, P.(eds) East Asian New Zealanders: research on new migrants Asia-Pacific Migration Research Network Research Papers Auckland: Department of Sociology, Massey University (Albany), 3-19

Goulter, J. (1996) The Asian equation - why immigrants plus money don't add up to a business boom New Zealand Business, $10(6)$ : 12-20
Levett, A. and Adams, A. (1987) Catching up with our future: the demand for Japan skills in New Zealand Wellington: New Zealand Japan Foundation

Lidgard, J. M. (1996) East Asian migration to Aotearoa/ New Zealand: perspectives of some new arrivals PSC Discussion Papers No. 12 Hamilton: Population Studies Centre, University of Waikato

New Zealand Immigration Service (1995a) Background paper: A Review of New Zealand's residence policies: the targeted immigration streams Wellington: New Zealand Immigration Service

New Zealand Immigration Service (1995b) New Zealand's 'targeted' immigration policies: summary of October 1995 policy changes, July 1995 Wellington: New Zealand Immigration Service

Shaw, C. M. (1996) Japanese language skills as an economic resource in New Zealand business (MPhil thesis) Palmerston North: Massey University

Trlin, A. D. (1993) The social effects and institutional structure of immigration in New Zealand in the 1980s, Asian and Pacific Migration Journal, 2: 1-25

Trlin, A.D. (1997) For the promotion of economic growth and prosperity: New Zealand's immigration policy 1991-1995 In Trlin, A. D. and Spoonley, P. (eds) New Zealand and intemational migration: a digest and bibliography No. 3 Palmerston North: Department of Sociology, Massey University, 1-27

Trlin, A. D., North, N., Pernice, R. and Henderson, A. (1998) The New Settlers Programme: encounters, responses, policies: an introduction to a research project. In Panny, R. (ed.) People - People - People: proceedings comments essays Third National Conference 1997 New Zealand Federation of Ethnic Councils Christchurch: New Zealand Federation of Ethnic Councils (Inc.), 274-290

Waite, J. (1992) Aoteareo: speaking for ourselves Part I and Part 2 Wellington: Learning Media

Watts, N. (1987) Foreign languages in exporting: results of a survey of the use of foreign languages by New Zealand exporters in 1986 Palmerston North: Department of Modern Languages, Massey University

Watts, N. (1992) The use of French in exporting and tourism: report on surveys conducted into the use of French in exporting and tourism in New Zealand in 1992 Palmerston North: Department of Linguistics and Second Language Teaching, Massey University

Watts, N. (1994) The use of foreign languages in tourism: research needs, Australian Review of Applied Linguistics, 17 (1): 73-84

Watts, N. and Williamson, V. (1994) Foreign languages and tourism in New Zealand: an examination of provider and client perceptions, In Conference Proceedings: Tourism Down-under Research Conference, 
December 1994 Palmerston North: Department of

Management Systems, Massey University, 45-54

\section{Authors}

Noel Watts is an Associate Professor in the

School of Language Studies,

and Andrew Trlin is an Associate Professor in the School of Policy Studies and Social Work at Massey University,

Private Bag 11222 ,

Palmerston North.

E-mail: N.R.Watts@massey.ac.nz

A.D.Trlin@massey.ac.nz 